"buried" in E15. The analysis, which was by this time complete, had to be redone and the Tables given in the later parts of the paper are correct. How this error was not discovered by at least one of the gangs of men who were responsible for burying another class of object is still a mystery.

The results of the two dowsers, experimenters six and seven, were not in Figs. 5 and 6 of Foulkes's article. The results of these experimenters were very interesting. They wandered off unsupervised (that is, without an accompanying "caddy" to record their responses). Their results were very similar for both types of ground. The results of experimenter six on the natural ground are given in Table 1.

Table 1 Dowsing Results of Experimenter Six on Natural Ground

\begin{tabular}{lrrrrrr}
\hline & \multicolumn{7}{c}{ Object buried } \\
& B & M & C & W & P & Totals \\
Response & & & & & & \\
M & 1 & 10 & 2 & 3 & 6 & 22 \\
P & 2 & 11 & 5 & 6 & 7 & 31 \\
O & 1 & 19 & 0 & 1 & 27 & 48 \\
(Blank) & 36 & 0 & 33 & 30 & 0 & 99 \\
Totals & 40 & 40 & 40 & 40 & 40 & 200 \\
\hline
\end{tabular}

B, Blank; M, metal mine; C, concrete block; W, wooden block; $P$, plastic mine.

Table 1 has a similar form to Table 2 in the article. On the original score card the dowser was instructed to record $\mathrm{M}$ for metallic mine, $P$ for plastic mine and $O$ for nothing present. When questioned about the response $O$ and the blanks left on the score sheet, experimenter seven said that $O$ had been used to mean that an object was present but its identity was unknown and that a blank had been left when a square had been dowsed and nothing found. Table 1 shows clearly a remarkable degree of association between the blank response and the presence of $\mathrm{B}, \mathrm{C}$ or $\mathrm{W}$ and between the $\mathrm{O}$ response and the presence of $\mathrm{M}$ or $\mathrm{P}$. Since the statement about the meaning of O was made " $a$ posteriori" it does not necessarily indicate an ability to dowse and as the two dowsers traversed the course together their results are not necessarily independent.

The experiment was therefore repeated by experimenter seven and his results are, in fact, those attributed in the article to experimenter eleven. There was no significant association on this second attempt without experimenter six, who was not retested. This dowser was the soldier illustrated in Fig. 3 of the article, a Nigerian, who unfortunately could not be retested. These results, although inconclusive because of the lack of experimental control, do suggest that something peculiar occurred on this occasion which might be worth further investigation. Two different conclusions, all too common in this type of work, can be drawn. Either some form of ability was demonstrated (although peculiarly recorded and interpreted) or a breach of security of the trial (including the possibility of cheating) took place. It can be argued that it would be possible for an unsupervised student to have prodded the ground (for example with one of the dowsing rods) and at least detected an object present, since for control purposes small wooden pegs indicated the position in which an object, if present, would have been buried. Although this form of cheating may well have taken place on this occasion it does not explain how mines and other objects might have been differentiated. Indeed, since the basic concern was with methods of detecting underground mines, a proven ability to detect the difference between a mine and an object (for example a stone), even by prodding, could have been of considerable importance.

There is also slight evidence that a positive response was more closely associated with the presence of a wooden block than with a concrete block-especially on the raked ground. Although this may be a spurious result, the wooden block may have absorbed more moisture than the concrete block, thus altering the drainage pattern and hence the surface appearance of the ground.

Ministry of Defence,

David G. SMith

Defence Operational Analysis Establishment,

Parvis Road,

West Byfleet,

Surrey

Received May 7, 1971.

${ }^{1}$ Foulkes, R. A., Nature, 229, 15 (1971).

\section{Dowsing Experiments Criticized}

MY photograph appeared in Foulkes's article, Dowsing Experiments $^{1}$, without prior reference to me, and I would like to make the following comments on the article.

The experiments carried out at the Military Engineering Experimental Establishment (MEXE) did not involve true "dowsing" as they were not water divining. Although experienced dowsers can locate buried objects such as cables, pipes and the like, these experiments were a search for objects unfamiliar to those taking part. Those I spoke to made no claim to achieve success, but agreed to the trial as an interesting experiment that might be of practical use. It was also evident to all that, to be of practical use, map dowsing must be used when walking over a live mine field. I agree that this experiment was a failure although one man was successful far beyond the bounds of chance.

The "flow in a pipe" experiment is not one which I would attempt, although I could probably locate the pipe either full or empty. No mention is made of the dowser's experience in this particular kind of search. I consider this test valueless, if he had no such experience.

I would like to emphasize that I was not instructing anyone in dowsing during the exercise at Chatham. The object was to find a number of men who could usefully develop into proficient water diviners. I do not think it possible to instruct anyone. Of those involved, $10 \%$, not $25 \%$, found accurately my second flow line; their judgment coinciding with mine and confirming my classification of them as sensitives.

I still maintain that the well referred to was correctly sited on one of the flows in the upper chalk. I predicted that the water would be near the bottom of the upper chalk and detectable by drilling through the clay to the chalk. This has not been done, as the drilling rig was removed before it had passed through the clay stratum. This was, therefore, not a dowsing failure.

The test over the 42 inch pipe seems to have been made by some of the $10 \%$ of "sensitives", who had no real dowsing experience. Even over natural fissure flows I would not have expected these novices to assess quantity.

Foulkes's description of the $\mathrm{V}$ rod movement was inaccurate. If the rod is held firmly in the normal way, another person can press the tip up or down, and, when released, the rod will return to its original position without any additional effort by the holder.

The Rocard experiment proves nothing. There are many dowsers who cannot dowse in rubber soled shoes. If Rocard, thinking he had used magnetized iron in his elbow joints, actually used non-magnetic iron, the experiment could have had the same result. It is a pity that Foulkes does not seem to have consulted any other authority than Rocard.

K. W. MerRylees

Blaize House,

Lavenham,

Suffolk

Received May 7, 1971.

${ }^{1}$ Foulkes, R. A., Nature, 229, 15 (1971). 